\title{
Topical Corticosteroids for Infectious Keratitis Before Culture-Proven Diagnosis
}

This article was published in the following Dove Press journal:

Clinical Ophthalmology

\author{
Koji Hirano (1D) \\ Hidenori Tanaka $\mathbb{( D}^{2}$ \\ Kumiko Kato (D) $^{3}$ \\ Kaoru Araki-Sasaki iD ${ }^{4}$ \\ 'Department of Ophthalmology, Fujita \\ Health University Bantane Hospital, \\ Nagoya, Aichi, 454-8509, Japan; \\ ${ }^{2}$ Department of Ophthalmology, Fujita \\ Health University School of Medicine, \\ Toyoake, Aichi, 470-I I92, Japan; \\ ${ }^{3}$ Department of Ophthalmology, Mie \\ University Graduate School of Medicine, \\ Tsu, Mie, 5I4-8507, Japan; ${ }^{4}$ Department \\ of Ophthalmology, Kansai Medical \\ University, Hirakata, Osaka, 573-1010, \\ Japan
}

Purpose: In clinical practice we sometimes encounter patients with severe corneal ulcers who have been treated with topical corticosteroids. This study reviewed the clinical features and visual outcomes of these patients and investigated the background of the prescription of topical corticosteroids.

Patients and Methods: The medical records of patients who visited the Cornea Service at Fujita Health University Bantane Hospital and were treated for infectious keratitis from April 2016 to March 2020 were retrospectively reviewed. Patients treated with topical corticosteroids before a culture-proven diagnosis were studied in terms of demographics, best-corrected visual acuity at arrival and at last visit, the clinical course after visit, ocular history, and combination therapy by the previous ophthalmologist.

Results: Out of the 200 eyes of 197 patients with infectious keratitis, 14 eyes of 14 patients were treated with topical corticosteroids before a culture-proven diagnosis. All 14 patients were referred, as they had severe keratitis that could not be cured with topical antibiotics and corticosteroids. Based on the culture results, we diagnosed Acanthamoeba keratitis (AK) in six patients, fungal keratitis (FK) in two patients, bacterial keratitis (including a suspected case) in two patients, and unknown cause in four patients. Two patients with AK, FK, and unknown keratitis had unfortunate clinical courses and poor visual outcomes. From the information in the referral letters, at least six of the 14 patients were treated with either acyclovir ocular ointment or valaciclovir tablets, along with topical corticosteroids.

Conclusion: Application of topical corticosteroids for keratitis that does not respond to empirical antibiotic therapy is harmful since AK or FK is likely involved in these topical antibiotic-resistant cases. Microbiological evidence, as well as a differential diagnosis of herpetic stromal keratitis, is needed when prescribing topical corticosteroid for the treatment of suspected infectious keratitis.

Keywords: culture-proven diagnosis, empiric antibiotic therapy, herpetic keratitis, infectious keratitis, topical corticosteroids

\section{Plain Language Summary}

In the corneal clinic of a university hospital in a metropolitan area, we sometimes encounter referred patients with severe corneal ulcers who have been treated with topical corticosteroids as well as antibiotic eye drops. Why were these topical corticosteroids prescribed? We retrospectively reviewed clinical records of patients with infectious keratitis treated with topical corticosteroids before a culture-proven diagnosis. During an investigative period of 4 years, 14 eyes of 14 patients were evaluated. All the patients were prescribed topical corticosteroids for the keratitis owing to unresponsive empirical antibiotic therapy, and at least six patients were treated for stromal keratitis due to herpes simplex virus.
Correspondence: Koji Hirano

Health University Bantane Hospital, 6-10,

Otoubashi 3-cho-me, Nakagawa-ku,

Nagoya, Aichi, 454-8509, Japan

Tel +8|-52-32|-8|7|

Fax +8I-52-322-4734

Email kojihira@fujita-hu.ac.jp 
Why did the corneal lesions of these patients worsen? Based on culture results, we diagnosed Acanthamoeba keratitis in six patients and fungal keratitis in two patients. Apart from bacterial keratitis, other microorganisms responsible for keratitis do not respond to antibiotic therapy, and the condition is worsened by the topical corticosteroids without appropriate anti-amoebic or anti-fungal therapy.

Application of topical corticosteroids for keratitis without microbiological evidence is harmful, and a differential diagnosis of herpetic stromal keratitis as well as fungal and Acanthamoeba keratitis is needed when using topical corticosteroid for the treatment of suspected infectious keratitis.

\section{Introduction}

The definitive diagnosis and specific therapy for microbial keratitis should only be determined by microbiological evaluation. $^{1-3}$ Nevertheless, the application of empirical antibiotic therapy without the use of smears or cultures cannot be rejected, as topical fluoroquinolone is associated with of a high success rate; moreover, the time and cost involved in performing cultures and maintaining the necessary materials are reduced. ${ }^{4-6}$

During the treatment of microbial keratitis, adjunctive topical corticosteroids are used to reduce the inflammatory response and subsequent corneal scarring, to obtain better visual outcomes, despite the possible risk of enhanced microbial replication, corneal melting, and steroid glaucoma. ${ }^{6-8}$ The safety and efficacy of topical corticosteroids for microbial keratitis have been reported ${ }^{9-17}$ in the Steroids for Corneal Ulcers Trial (SCUT) $)^{9,10}$ and other randomized control studies. ${ }^{11,12}$ The consensus of these studies was that unlike the use of topical antibiotics, the empirical use of topical corticosteroids for suspected microbial keratitis is not recommended. According to the Bacterial Keratitis Preferred Practice Pattern ${ }^{\circledR}$ 2018, 24-48 hours after the causative organism has been identified and/ or infection is responding to therapy, corticosteroids may be considered, and close follow-up by a corneal specialist is recommended. Corticosteroids should be avoided in bacterial keratitis caused by slow-cycling microbes such as Nocardia, ${ }^{10}$ and fungal keratitis, ${ }^{7,11,18}$ while in Acanthamoeba keratitis, maintaining adequate antiamoebic therapy is needed if a topical corticosteroid is used. $^{19-23}$ Therefore, these microorganisms should be ruled out and a definitive diagnosis of bacterial keratitis based on smear and culture or by confirming the response to anti-microbial therapy is suggested before topical corticosteroids. $^{24}$
At the corneal clinic of our institution and hospital in a metropolitan area, which serves a population of 4 million, we sometimes encounter referred patients with severe corneal ulcers who have been treated with topical corticosteroids. The purpose of this study was to review the clinical features and the visual outcomes of these patients, and to elucidate the effect of the empirical use of topical corticosteroids on the clinical course of this condition and the background of steroid applications in such patients.

\section{Patients and Methods}

We retrospectively reviewed the medical records of patients who visited the Cornea Service at Fujita Health University Bantane Hospital and were treated for infectious keratitis from April 2016 to March 2020. The diagnosis of microbial infectious keratitis was confirmed by culture, but because the antibiotic therapy had already been started before the patients arrived at our institution, many of them were solely diagnosed based on the corneal findings and the clinical course.

Suspected infectious keratitis patients treated with topical corticosteroids before culture-proven diagnosis were retrospectively studied in terms of demographics, bestcorrected visual acuity at arrival and at the last visit, clinical course after the initial visit, ocular history, and combination therapy by the previous ophthalmologist. We used this information to determine the influence of topical steroid therapy and to determine the factors that led to the steroid prescription.

This study was approved by the institutional review board of the Fujita Health University Faculty of Medicine (Approval number: C120-135). Informed consent was obtained from each patient for use in clinical records for future research.

\section{Results}

\section{Patients' Visits}

Two hundred eyes of 197 patients were treated for microbial infectious keratitis in the investigation period. Among the 197 patients, 195 eyes of 192 patients were referred from a hospital or ophthalmic clinic. Almost all the referred patients had already been empirically treated with topical or systemic antibiotic therapy, and the reason for the referral was a poor response to the antibiotic therapy.

Among the referred patients, 14 eyes of 14 patients had been treated with corticosteroid eye drops before arrival (Table 1). 


\section{Use of Topical Corticosteroids}

Corticosteroid eye drops were not used before keratitis occurred but were used to treat the corneal lesions. Out of the 14 patients, six patients were prescribed topical corticosteroids by the referring doctor, and eight patients were prescribed these drugs by another doctor (Table 1). The details of the medical practice, other than the referring doctor, at the previous doctor's clinic were unknown, but the prescribed corticosteroid eye drops were $0.1 \%$ betamethasone sodium phosphate for nine patients, $0.1 \%$ fluorometholone for two patients, and unknown steroid eye drops for three patients. Among the nine patients who were treated with $0.1 \%$ betamethasone sodium phosphate, combined corticosteroidantibiotic eye drops (betamethasone sodium sulfate/

Table I Patients in Whom Topical Corticosteroids Were Applied Before Culture: Demographics and Past Treatments Other Than Topical Antibiotics

\begin{tabular}{|c|c|c|c|c|c|c|c|c|c|c|c|}
\hline $\begin{array}{l}\text { Case } \\
\text { No. }\end{array}$ & $\begin{array}{l}\text { Age } \\
\text { (Years) }\end{array}$ & Sex & Laterality & $\begin{array}{l}\text { Onset- } \\
\text { Arrival } \\
\text { (Days) }\end{array}$ & $\begin{array}{l}\text { Steroid } \\
\text { Eye } \\
\text { Drops }\end{array}$ & $\begin{array}{l}\text { Prescribing } \\
\text { Doctor }\end{array}$ & $\begin{array}{l}\text { Steroid } \\
\text { Use } \\
\text { (Days) }\end{array}$ & $\begin{array}{l}\text { CL } \\
\text { User }\end{array}$ & $\begin{array}{l}\text { Ocular } \\
\text { History }\end{array}$ & $\begin{array}{l}\text { Anti- } \\
\text { HSV } \\
\text { Drugs }\end{array}$ & Diagnosis \\
\hline 1 & 32 & Male & L & 7 & Unknown & $\begin{array}{l}\text { Previous } \\
\text { doctor }\end{array}$ & 4 & Yes & & & BK \\
\hline 2 & 82 & Male & $\mathrm{R}$ & 50 & $\begin{array}{l}0.1 \% \text { BM } \\
+ \text { Fra }\end{array}$ & $\begin{array}{l}\text { Referral } \\
\text { doctor }\end{array}$ & 30 & & $\begin{array}{l}\text { DMR, } \\
\text { Rubeotic } \\
\text { gla }\end{array}$ & & BK susp \\
\hline 3 & 39 & Male & $R$ & 12 & $0.1 \% \mathrm{FLM}$ & $\begin{array}{l}\text { Previous } \\
\text { doctor }\end{array}$ & 7 & Yes & & $A C V$ & AK \\
\hline 4 & 24 & Male & $R$ & 30 & $\begin{array}{l}0.1 \% \mathrm{BM} \\
+ \text { Fra }\end{array}$ & $\begin{array}{l}\text { Previous } \\
\text { doctor }\end{array}$ & 28 & Yes & $\begin{array}{l}\text { Herpetic } \\
\text { keratitis }\end{array}$ & VACV & AK \\
\hline 5 & 53 & Female & L & 75 & $0.1 \%$ BM & $\begin{array}{l}\text { Previous } \\
\text { doctor }\end{array}$ & 60 & Yes & $\begin{array}{l}\text { Herpetic } \\
\text { keratitis }\end{array}$ & & $A K$ \\
\hline 6 & 31 & Male & $\mathrm{R}$ & 18 & $0.1 \%$ BM & $\begin{array}{l}\text { Previous } \\
\text { doctor }\end{array}$ & 10 & Yes & & & AK \\
\hline 7 & 56 & Male & L & 14 & $0.1 \% \mathrm{BM}$ & $\begin{array}{l}\text { Referral } \\
\text { doctor }\end{array}$ & 8 & Yes & & $A C V$ & AK \\
\hline 8 & 33 & Female & L & 240 & Unknown & $\begin{array}{l}\text { Referral } \\
\text { doctor }\end{array}$ & 30 & & $\begin{array}{l}\text { Herpetic } \\
\text { keratitis }\end{array}$ & & AK \\
\hline 9 & 46 & Female & $R$ & 20 & $\begin{array}{l}0.1 \% \mathrm{BM} \\
+ \text { Fra }\end{array}$ & $\begin{array}{l}\text { Previous } \\
\text { doctor }\end{array}$ & 15 & Yes & & & FK \\
\hline 10 & 48 & Female & $R$ & 21 & $0.1 \%$ FLM & $\begin{array}{l}\text { Referral } \\
\text { doctor }\end{array}$ & 7 & & & $\begin{array}{l}\text { ACV, } \\
\text { VACV }\end{array}$ & FK \\
\hline II & 44 & Female & L & 14 & $0.1 \% \mathrm{BM}$ & $\begin{array}{l}\text { Referral } \\
\text { doctor }\end{array}$ & 3 & Yes & & & Unknown \\
\hline 12 & 19 & Female & L & 30 & Unknown & $\begin{array}{l}\text { Previous } \\
\text { doctor }\end{array}$ & 21 & Yes & & & Unknown \\
\hline 13 & 51 & Male & $\mathrm{R}$ & 14 & $0.1 \%$ BM & $\begin{array}{l}\text { Referral } \\
\text { doctor }\end{array}$ & 3 & & & $\begin{array}{l}\text { ACV, } \\
\text { VACV }\end{array}$ & Unknown \\
\hline 14 & 35 & Male & L & 40 & $0.1 \%$ BM & $\begin{array}{l}\text { Previous } \\
\text { doctor }\end{array}$ & 28 & & $\begin{array}{l}\text { Herpetic } \\
\text { keratitis }\end{array}$ & ACV & Unknown \\
\hline
\end{tabular}

Abbreviations. No., number; CL, contact lenses; HSV, herpes simplex virus; R, right; L, left; FLM, fluorometholone; BM, betamethasone sodium phosphate; BM+Fra, combined betamethasone sodium sulfate and fradiomycin sulfate; AK, Acanthamoeba keratitis; BK, bacterial keratitis; FK, fungal keratitis; PDR, proliferative diabetic retinopathy; rubeotic gla, rubeotic glaucoma; ACV, acyclovir ocular ointment; VACV, valaciclovir tablets. 
fradiomycin sulfate) were prescribed for at least three patients (Table 1).

All patients visited the ophthalmic clinic with a complaint of ocular pain, red eye, and visual disturbance. Nine patients were contact lens wearers (Table 1).

\section{History of Herpetic Keratitis}

The history of herpetic keratitis and treatment is described in Table 1. According to the referral letters, four patients (cases 4, 5, 8, and 14) had a past history of herpetic keratitis, but the details and the accuracy of the diagnosis were unknown. At least six of the 14 patients were treated with either acyclovir ocular ointment or valaciclovir tablets, along with topical corticosteroids (cases 3, 4, 7, 10, 13, 14). Although we could not exclude concurrent herpetic stromal keratitis because our institution did not have the facility to perform either the immune chromatography or the real-time polymerase chain reaction, the corneal findings and the clinical course of the patients' eyes were not suggestive of herpetic necrotic keratitis.

\section{Culture and Diagnosis}

Corneal scraping and culture were performed for 13 patients (Table 2); however, because the cornea was already perforated and Acanthamoeba was proven by the referral doctor, culture was not performed for case 8. As listed in Table 2, based on the results of the cultures, we diagnosed keratitis as follows: bacterial keratitis in two patients including one suspected case, Acanthamoeba keratitis in six patients, fungal keratitis in two patients, and unknown cause in four patients. Case 2 had a corneal ulcer with a $3.0-\mathrm{mm}$ diameter and hypopyon at the first visit, but the inflammation subsided within 3 weeks of topical antibiotic therapy, and we thus diagnosed the patient with bacterial keratitis even though the culture was negative. In four patients with unknown causes (cases 11-14), the diagnosis of microbial infectious keratitis was made from the clinical presentation at the first visit (Figure 1), but it was not possible to determine whether these were bacterial, fungal, or Acanthamoeba keratitis cases based on the clinical course.

Table 2 Patients Topical Corticosteroids Were Applied Before Culture: Culture Results and Prognosis

\begin{tabular}{|c|c|c|c|c|c|c|}
\hline $\begin{array}{l}\text { Case } \\
\text { No. }\end{array}$ & $\begin{array}{r}\text { BCVA at First } \\
\text { Visit }\end{array}$ & $\begin{array}{r}\text { BCVA at Last } \\
\text { Visit }\end{array}$ & $\begin{array}{l}\text { Weeks Taken to } \\
\text { Settle Down }\end{array}$ & Cultured Microorganisms & Diagnosis & $\begin{array}{l}\text { Corneal } \\
\text { Perforation }\end{array}$ \\
\hline I & HM & 0.3 & 3 & Pseudomonas aeruginosa & BK & \\
\hline 2 & NLP & NLP & 8 & No growth & BK susp & \\
\hline 3 & 0.4 & 1.0 & 17 & $\begin{array}{l}\text { Amoeba, Staphylococcus epidermis, } \\
\text { GM Pos bacilli }\end{array}$ & AK & \\
\hline 4 & LP & 0.4 & 22 & Amoeba, Staphylococcus epidermis & AK & \\
\hline 5 & $\mathrm{CF}$ & HM & 50 & Amoeba & AK & \\
\hline 6 & HM & 0.9 & 15 & Amoeba & AK & \\
\hline 7 & 0.3 & 0.9 & 19 & Amoeba & AK & \\
\hline 8 & LP & LP & 8 & Amoeba at referring doctor & AK & Yes \\
\hline 9 & HM & NLP & Evisceration & Fusarium sp. & FK & Yes \\
\hline 10 & LP & NLP & Evisceration & Fusarium sp. & FK & Yes \\
\hline II & 0.03 & 0.8 & 3 & No growth & Unknown & \\
\hline 12 & $\mathrm{CF}$ & 0.5 & 6 & No growth & Unknown & \\
\hline 13 & LP & 0.05 & 25 & No growth & Unknown & Yes \\
\hline 14 & 0.04 & 0.04 & 30 & Staphylococcus epidermis (MRSE) & Unknown & \\
\hline
\end{tabular}

Abbreviations: BCVA, best-corrected visual acuity; HM, hand motion; NLP, no light perception; LP, light perception; CF, counting fingers; GM Pos bacilli, Gram-positive bacilli; AK, Acanthamoeba keratitis; BK, bacterial keratitis, FK, fungal keratitis; MRSE, methicillin-resistant Staphylococcus epidermis. 


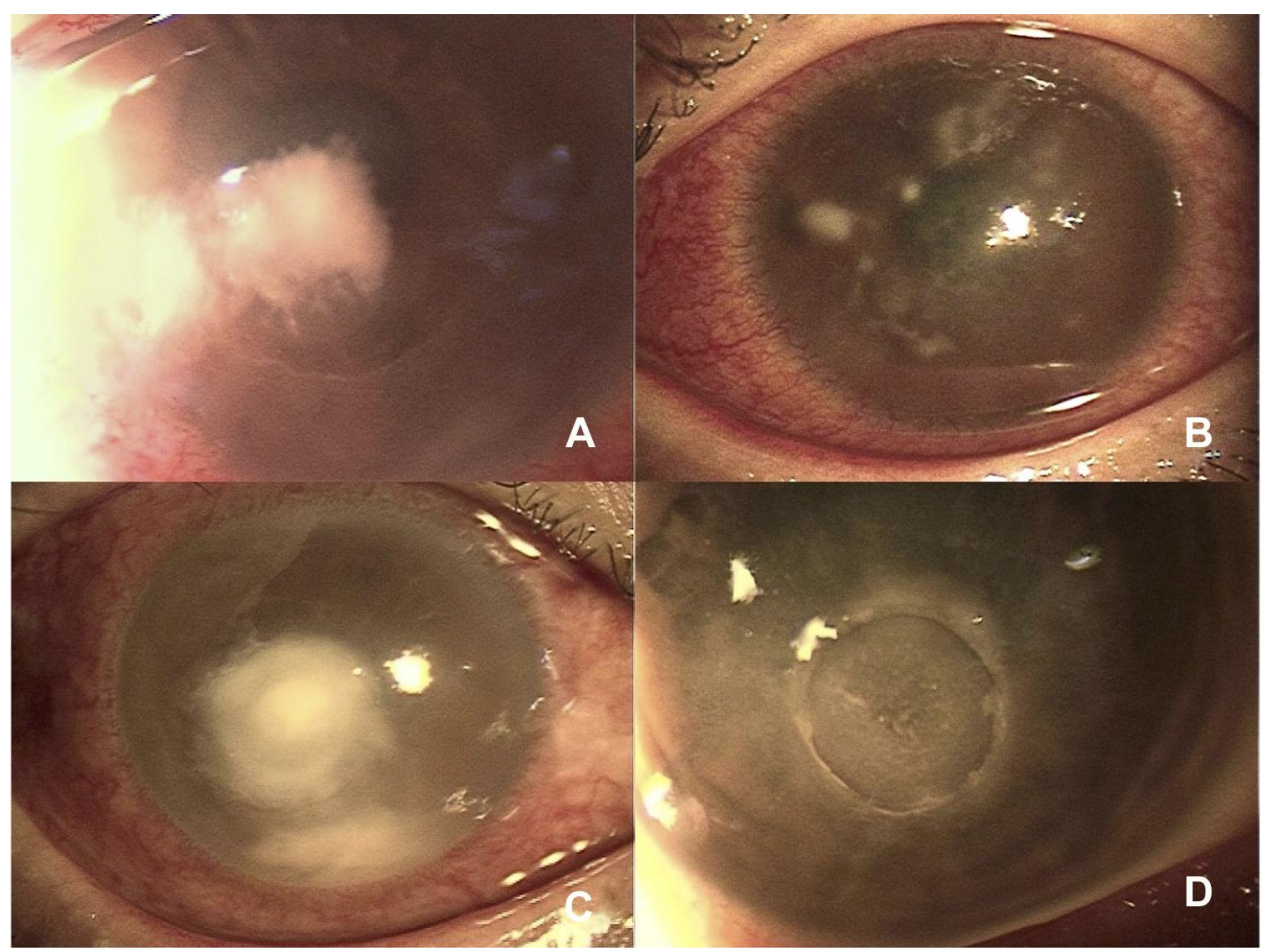

Figure I Cases of suspected infectious keratitis who were treated with topical corticosteroids without culture-proven diagnosis and before presentation to our clinic. (A) Case II; Forty-four-year-old female. Although fungal keratitis was suspected based on corneal findings, it took only 3 weeks to cure the inflammation by a combination of topical antibiotics and anti-fungal therapy. (B) Case 12; Eighteen-year-old female. Early stage of Acanthamoeba keratitis was suspected based on the findings, but no organism could be cultured, even after co-culture with Escherichia coli. (C) Case 13; Fifty-one-year-old male. Despite treatment with a combination topical antibiotic and antifungal therapy, corneal perforation occurred 2 weeks after the first visit. (D) Case 14; Thirty-five-year-old male. Culture was attempted 3 times from the first visit, and at the second time of culture, I week after the intensive topical antibiotic therapy was started, methicillin-resistant Staphylococcus epidermis was detected by enrichment culture, but the significance of this result was unclear.

\section{Prognosis}

The prognosis is summarized in Table 2. The patients with bacterial keratitis (cases 1 and 2) responded well to the topical antibiotic therapy, and the corneal lesion healed as a scar after 3 weeks, after which corticosteroid eye drops were started again to settle the infiltration.

The prognosis for the vision of the two patients with Acanthamoeba keratitis (cases 5 and 8) whose anti-amoebic therapy was started more than 10 weeks after the onset was poor (Table 1). In patients with Acanthamoeba keratitis in whom appropriate anti-amoebic therapy was started at least within 2 weeks from the onset, the visual prognosis was good, even though topical corticosteroids were applied before the diagnosis (cases 3, 6, and 7).

Both patients with fungal keratitis visited the specialist clinic 3 weeks after the onset of the complaint (Table 1). The delay in the diagnosis and identification of the causative organism (Fusarium species), in addition to the use of topical corticosteroid before diagnosis, may have caused a corneal perforation and loss of sight in the affected eyes (cases 9 and 10).
In the five culture-negative cases, we could not determine the causative microorganism based on the corneal appearance and the clinical course in four cases (Figure 1). Favorable recovery of vision has still not been obtained in two of the cases (cases 13 and 14). This may be due to the difficulty in establishing a treatment plan because the empirical topical antibiotic and corticosteroid treatment has masked the appearance of the corneal lesion.

\section{Discussion}

Similar to the findings of the SCUT study, in our cases, the use of topical steroids along with antibiotics did not affect the vision prognoses in the eyes with bacterial keratitis; however, vision was lost in two eyes with fungal keratitis (Table 2). Even though this poor outcome may be attributed to the Fusarium sp. that was involved in two of our cases, topical corticosteroids should not be used for fungal keratitis. ${ }^{6,7,18}$ For the eyes with Acanthamoeba keratitis, topical corticosteroids are not contraindicated as long as appropriate anti-amoebic therapy is applied. ${ }^{19-21}$ However, two of the six Acanthamoeba keratitis eyes lost vision in our study (Table 2). In the Acanthamoeba 
keratitis patients (cases 5 and 8) as well as in two fungal keratitis patients (cases 9 and 10) and two unknown keratitis patients (cases 13 and 14), one of the reasons for the undesirable visual prognosis could be the delay in proper diagnosis (Table 1), caused by the masked clinical findings (Figure 1) and the reactions to the empirical use of topical antibiotics and corticosteroids. $^{25,26}$

From the referral letter information, at least eight patients were assumed to be treated with topical corticosteroids after being diagnosed with stromal herpetic keratitis. Three of the six Acanthamoeba keratitis patients, one of the two fungal keratitis patients, and two of the four unknown keratitis patients were treated with acyclovir ointment or valaciclovir tablets (Table 1). In addition to these patients who were treated with anti-herpes virus drugs, two Acanthamoeba keratitis patients had a history of herpetic keratitis, according to the referral letter (Table 2). These facts show that we have to distinguish whether the keratitis is stromal keratitis related to herpes simplex virus or microbial infectious keratitis.

From the results of this study, we concluded that it is important to evaluate the patient for fungal keratitis and Acanthamoeba keratitis before deciding on the use of topical corticosteroids for the treatment of the keratitis. Because correct differentiation of bacterial or fungal keratitis by the clinical signs or findings is difficult even for a corneal specialist, ${ }^{27}$ it is important to make a biologically proven diagnosis by smear and culture before prescribing topical corticosteroids. In addition, it is important to stop the application of topical corticosteroids immediately when keratitis does not improve by these steroids.

A combination of $0.1 \%$ betamethasone sodium sulfate and fradiomycin sulfate was prescribed in at least three of the 14 cases. Along with the possibility of stromal herpetic keratitis, another possible reason for the immediate use of topical corticosteroids could be the commercial availability of corticosteroid-antibiotic combination eye drops. As O'Day DM pointed out, ${ }^{28}$ these preparations have the potential to violate the rule of combined corticosteroidantibiotic therapy for infectious keratitis.

Accordingly, microbiological evidence, as well as a differential diagnosis of herpetic stromal keratitis, is needed when prescribing topical corticosteroids for the treatment of infectious keratitis. Although corticosteroidantibiotic combination eye drops seem safe, they are meaningless or unsafe for treating infectious keratitis other than culture-proven bacterial keratitis.

In addition to its retrospective nature, the main limitation of this study was the single-center study design. As almost all the patients had already been treated empirically with topical antibiotics by the previous ophthalmologist, it was difficult to distinguish the causative microorganism by culture. Thus, we had to diagnose the keratitis as infectious keratitis, particularly bacterial keratitis, based on the corneal findings and clinical course. Additional information from other institutions is needed to clarify the merits and demerits, as well as the background for the empirical use of topical corticosteroids for suspected microbial infectious keratitis.

\section{Conclusion}

This study reported a series of severe infectious keratitis cases referred to a specialized medical institution, who were given an antibiotic-steroid combination treatment. Our findings show that it is harmful to apply topical corticosteroids for keratitis that does not respond to empirical antibiotic therapy, since Acanthamoeba keratitis or fungal keratitis are likely involved in these topical antibiotic-resistant cases.

The use of topical corticosteroids along with empirical antibiotic therapy make it difficult to distinguish the causative agent of the infection in suspected keratitis, either by culture or by the corneal findings and clinical course, and as a result, may delay the appropriate treatment and cause unfortunate outcomes. Therefore, we conclude that the use of topical corticosteroids, merely owing to ineffective empirical antibiotic therapy for keratitis, should be avoided. Microbiological evidence, as well as a differential diagnosis of herpetic stromal keratitis, is needed before prescribing topical corticosteroids for the treatment of suspected infectious keratitis.

\section{Abbreviations}

AK, Acanthamoeba keratitis; FK, fungal keratitis; SCUT, Steroids for Corneal Ulcers Trial.

\section{Data Sharing Statement}

The datasets used and/or analyzed during the current study are available from the corresponding author upon reasonable request.

\section{Ethics Approval and Consent to Participate}

Written informed consent was obtained from each patient. This study was approved by the Research Ethics Committee of Fujita Health University and was performed in accordance with the Declaration of Helsinki. 


\section{Consent for Publication}

Written informed consent was obtained from the participants for publication of the research article and any accompanying images.

\section{Author Contributions}

$\mathrm{KH}$ followed all the patients in this study and wrote the manuscript. KH, HT, and KK analyzed and interpreted the data on the clinical features of the patients. KK and KA-S made critical comments on the manuscript and provided input regarding the clinical outcome of the series of patients with infectious keratitis in whom topical corticosteroids were used. All authors made substantial contributions to conception and design, acquisition of data, or analysis and interpretation of data; took part in drafting the article or revising it critically for important intellectual content; agree to submit to the current journal; gave final approval of the version to be published; and agree to be accountable for aspects of the work.

\section{Funding}

This study was supported by a grant from the Fujita Gakuen Research Fund and the Alcon Japan Research Grant.

\section{Disclosure}

The authors report no conflicts of interest in this work.

\section{References}

1. Ogawa GSH, Hyndiuk RA. Clinical disease (bacterial keratitis and conjunctivitis). In: Smolin G, Thoft RA, editors. The Cornea. 3rd ed. Boston: Little, Brown, and Company; 1994:130-133.

2. Dahlgren MA, Lingappan A, Wilhelmus KR. The clinical diagnosis of microbial keratitis. Am J Ophthalmol. 2007;143(6):940-944. doi:10.1016/j.ajo.2007.02.030

3. Austin A, Lietman T, Rose-Nussbaumer J. Update on the management of infectious keratitis. Ophthalmology. 2017;124(11):1678-1689. doi:10.1016/j.ophtha.2017.05.012

4. McDonnell PJ, Nobe J, Gauderman WJ, et al. Community care of corneal ulcers. Am J Ophthalmol. 1992;114(5):531-538. doi:10.1016/ S0002-9394(14)74479-4

5. Rodman RC, Spisak S, Sugar A, et al. The utility of culturing corneal ulcers in a tertiary referral center versus a general ophthalmology clinic. Ophthalmology. 1997;104(11):1897-1901. doi:10.1016/S01616420(97)30010-4

6. Lin A, Rhee MK, Akpek E, et al. Bacterial keratitis preferred practice pattern $^{\circledR}$. Ophthalmology. 2019;126(1):P1-P55

7. Stern GA, Buttross M. Use of corticosteroids in combination with antimicrobial drugs in the treatment of infectious corneal disease. Ophthalmology. 1991;98(6):847-853. doi:10.1016/S0161-6420(91) 32211-5

8. Hindman HB, Patel SB, Jun AS. Rationale for adjunctive topical corticosteroids in bacterial keratitis. Arch Ophthalmol. 2009;127 (1):97-102. doi:10.1001/archophthalmol.2008.504
9. Srinivasan M, Mascarenhas J, Rajaraman R, et al. Corticosteroids for bacterial keratitis: the Steroids for Corneal Ulcer Trial (SCUT). Arch Ophthalmol. 2012;130(2):143-150. doi:10.1001/archophthal mol.2011.315

10. Srinivasan M, Mascarenhas J, Rajaraman R, et al. The Steroids for Corneal Ulcer Trial (SCUT): secondary 12-month clinical outcome of a randomized controlled trial. Am J Ophthalmol. 2014;157 (2):327-333. doi:10.1016/j.ajo.2013.09.025

11. Carmichael TR, Gelfand Y, Welsh NH. Topical steroids in the treatment of central and paracentral corneal ulcers. $\mathrm{Br} J$ Ophthalmol. 1990;74(9):528-531. doi:10.1136/bjo.74.9.528

12. Blair J, Hodge W, Al-Ghamdi S, et al. Comparison of antibiotic-only and antibiotic-steroid combined treatment in corneal ulcer patients: double-blinded randomized clinical trial. Can J Ophthalmol. 2011;46 (1):40-45. doi:10.3129/i10-054

13. Palioura S, Henry CR, Amescua G, Alfonso EC. Role of steroids in the treatment of bacterial keratitis. Clin Ophthalmol. 2016;10:179-186. doi:10.2147/OPTH.S80411

14. Jones DB. Corticosteroids for bacterial keratitis. Who gets them? JAMA Ophthalmol. 2013;131(2):233-234. doi:10.1001/ jamaophthalmol.2013.1610

15. Wilhelmus KR. Indecision about corticosteroids for bacterial keratitis. An evidence-based update. Ophthalmology. 2002;109 (5):835-844. doi:10.1016/S0161-6420(02)00963-6

16. Ni N, Srinivasan M, McLeod SD, et al. Use of adjunctive corticosteroids in bacterial keratitis. Curr Opin Ophthalmol. 2016;27 (4):353-357. doi:10.1097/ICU.0000000000000273

17. Cohen EJ. The case against the use of steroids in the treatment of bacterial keratitis. Arch Ophthalmol. 2009;127(1):103-104. doi:10.1001/archophthalmol.2008.503

18. Henry CR, Flynn HW, Miller D, Forster RK, Alfonso EC. Infectious keratitis progressing to endophthalmitis: a 15-year-study of microbiology, associated factors, and clinical outcomes. Ophthalmology. 2012;119(12):2443-2449. doi:10.1016/j.ophtha.2012.06.030

19. McClellan K, Howard K, Niederkorn JY, Alizadeb H. Effect of steroids on Acanthamoeba cysts and trophozoites. Invest Ophthalmol Vis Sci. 2001;42(12):2885-2893.

20. Park DH, Palay DA, Daya SM, Stulting RD, Krachmer JH, Holland EJ. The role of topical corticosteroids in the treatment of Acanthamoeba keratitis. Cornea. 1997;16(3):277-283. doi:10.1097/00003226199705000-00004

21. Dart JK, Saw VPJ, Kilvington S. Acanthamoeba keratitis: diagnosis and treatment update 2009. Am J Ophthalmol. 2009;148(4):487-499. doi:10.1016/j.ajo.2009.06.009

22. D’Aversa G, Stern GA, Driebe WT Jr. Diagnosis and successful medical treatment of Acanthamoeba Keratitis. Arch Ophthalmol. 1995;113(9):1120-1123. doi:10.1001/ archopht.1995.01100090046021

23. Hirano K. Factors which affect the progression and severity of Acanthamoeba keratitis. Nippon Ganka Gakkai Zasshi. 2011;115 (10):899-904.

24. Tuli SS. Topical corticosteroids in the management of bacterial keratitis. Curr Ophthalmol Rep. 2013;1(4):190-193. doi:10.1007/ s-40135-013-0026-0

25. Marangon FB, Miller D, Alfonso EC. Impact of prior therapy on the recovery and frequency of corneal pathogens. Cornea. 2004;23 (2):158-164. doi:10.1097/00003226-200403000-00009

26. Miedziak AI, Miller MR, Rapuano CJ, Libson PR, Cohen EJ. Risk factors in microbial keratitis leading to penetrating keratoplasty. Ophthalmology. 1999;106(6):1166-1171. doi:10.1016/S0161-6420(99)90250-6

27. Dalmon C, Porco TC, Lietman TM, et al. The clinical differentiation of bacterial and fungal keratitis: a photographic survey. Invest Ophthalmol Vis Sci. 2012;53(4):1787-1791. doi:10.1167/iovs.118478

28. O'Day DM. Corticosteroids: an unresolved debate. Ophthalmology. 1991;98(6):845-846. doi:10.1016/S0161-6420(91)32212-7 


\section{Publish your work in this journal}

Clinical Ophthalmology is an international, peer-reviewed journal covering all subspecialties within ophthalmology. Key topics include: Optometry; Visual science; Pharmacology and drug therapy in eye diseases; Basic Sciences; Primary and Secondary eye care; Patient Safety and Quality of Care Improvements. This journal is indexed on PubMed
Central and CAS, and is the official journal of The Society of Clinical Ophthalmology (SCO). The manuscript management system is completely online and includes a very quick and fair peer-review system, which is all easy to use. Visit http://www.dovepress.com/ testimonials.php to read real quotes from published authors. 